\title{
The effects of strength and power training on single-step balance recovery in older adults: a preliminary study
}

This article was published in the following Dove Press journal:

Clinical Interventions in Aging

17 April 2014

Number of times this article has been viewed

\author{
Derek N Pamukoff' \\ Eric C Haakonssen' \\ Joseph A Zaccaria' \\ Michael L Madigan ${ }^{2}$ \\ Michael E Miller ${ }^{3}$ \\ Anthony P Marsh' \\ 'Department of Health and \\ Exercise Science, Wake Forest \\ University, Winston-Salem, NC, \\ USA; ${ }^{2}$ Department of Engineering \\ Science and Mechanics, Center \\ for Gerontology, Virginia Tech- \\ Wake Forest School of Biomedical \\ Engineering and Sciences, Blacksburg, \\ VA, USA; ${ }^{3}$ Department of Biostatistical \\ Sciences, Wake Forest School of \\ Medicine, Winston-Salem, NC USA
}

\begin{abstract}
Improving muscle strength and power may mitigate the effects of sarcopenia, but it is unknown if this improves an older adult's ability to recover from a large postural perturbation. Forward tripping is prevalent in older adults and lateral falls are important due to risk of hip fracture. We used a forward and a lateral single-step balance recovery task to examine the effects of strength training (ST) or power (PT) training on single-step balance recovery in older adults. Twenty older adults (70.8 \pm 4.4 years, eleven male) were randomly assigned to either a 6 -week (three times/week) lower extremity ST or PT intervention. Maximum forward $\left(\right.$ FLean $\left._{\max }\right)$ and lateral $\left(\right.$ LLean $\left._{\max }\right)$ lean angle and strength and power in knee extension and leg press were assessed at baseline and follow-up. Fifteen participants completed the study (ST =7, PT =8). Least squares means $(95 \% \mathrm{CI})$ for $\Delta$ FLean $_{\text {max }}\left(\mathrm{ST}:+4.1^{\circ}[0.7,7.5]\right.$; PT: $\left.+0.6^{\circ}[-2.5,3.8]\right)$ and $\Delta$ LLean $_{\max }\left(\mathrm{ST}:+2.2^{\circ}[0.4,4.1]\right.$; PT: $\left.+2.6^{\circ}[0.9,4.4]\right)$ indicated no differences between groups following training. In exploratory post hoc analyses collapsed by group, $\Delta$ FLean ${ }_{\text {max }}$ was $+2.4^{\circ}$ $(0.1,4.7)$ and $\Delta$ LLean $_{\max }$ was $+2.4^{\circ}(1.2,3.6)$. These improvements on the balance recovery tasks ranged from $\sim 15 \%-30 \%$. The results of this preliminary study suggest that resistance training may improve balance recovery performance, and that, in this small sample, PT did not lead to larger improvements in single-step balance recovery compared to ST.
\end{abstract}

Keywords: resistance exercise, falls, muscle strength, muscle power, exercise intervention, randomized trial

\section{Introduction}

Falls in older adults are a significant public health problem because the prevalence of falls is elevated among older adults and the consequences are severe. Approximately $95 \%$ of all hip fractures each year are attributed to falls, ${ }^{1}$ and $20 \%-30 \%$ of those who fall and suffer a hip fracture die within 1 year. $^{2}$ The rapid growth in the number of older adults coupled with the high costs associated with non-fatal falls ${ }^{3}$ demands that effective fall prevention strategies are identified and tested.

Muscular strength and power are important for the maintenance of balance. ${ }^{4-7}$ Therefore, it has been suggested that lower limb muscle power (product of muscle force and velocity) may be more influential than lower limb strength when stepping to recover balance and avert a fall after a large postural perturbation. ${ }^{4,6}$ In fact, fallers have less lower limb muscle power than non-fallers. ${ }^{6}$ To our knowledge, no study has investigated the effects of muscle strength training (ST) or power training (PT) on balance recovery following a large postural perturbation.

A commonly used method of testing balance recovery after a large postural perturbation is to release an individual from a static forward leaning position and have them
Correspondence: Anthony P Marsh Wake Forest University, Department of Health and Exercise Science, PO Box 7868, Winston-Salem, NC 27109, USA Tel +I 3367584643

Fax +I 3367584680

Email marshap@wfu.edu 
attempt recovery with a single step. ${ }^{8-16}$ Madigan $^{12}$ reported that muscle power generated during single-step recovery on the forward leaning task was lower in older compared to younger men. He speculated that increasing peak muscle power may lead to an increase in the maximum lean angle from which a person could recover in a single step. Additionally, Carty et al ${ }^{17}$ compared balance recovery between males and females and found that an inability to generate sufficient power in the stepping limb was a limiting factor in a single-step recovery from a forward loss of balance. Similarly, knee extensor joint torques during single step balance recovery are also lower in older compared to younger subjects during single-step recovery, ${ }^{16,18}$ and lower limb weakness is negatively correlated with performance on forward leaning tasks. ${ }^{9}, 17$ Therefore, strength training may also be an effective intervention that prevents buckling of the knee during the support phase of balance recovery, leading to improved balance recovery performance. ${ }^{16,18-20}$

Examining balance recovery after a forward loss of balance is important due to the high prevalence of falls after tripping. ${ }^{21}$ However, descriptors of medial-lateral stability in older adults are also associated with falls and future risk of falling. ${ }^{22-26}$ Deficits in lateral stability prospectively predict falls ${ }^{26}$ and older adults are less efficient at recovering from a lateral perturbation compared to younger adults. ${ }^{27}$ In addition, lateral falls increase the likelihood of impacting the hip. Only one study, ${ }^{8}$ to our knowledge, has examined single-step recovery in a lateral direction, reporting that older adults had smaller maximal lateral lean angles compared to young adults. Currently, there are no data on the influence of resistance exercise on lateral leaning performance in older persons.

Therefore, the purpose of this 6-week pilot study was to add unique information to the literature by 1) examining the short-term effects of PT and ST on single-step balance recovery in older men and women in a forward direction and 2) to examine the effects of these interventions on balance recovery in the lateral direction..$^{28}$ Our goal was to obtain estimates of variances to inform a future randomized trial.

\section{Methods}

\section{Participants and study design overview}

Twenty community-dwelling older adults (eleven males, nine females) were recruited using research participant registries and newsletters. The study was approved by the Wake Forest University Institutional Review Board and all participants provided written informed consent. Inclusion criteria were an age of 65-79 years and physician clearance prior to the start of resistance exercise. Exclusion criteria were a psychiatric illness; symptomatic heart disease; resting blood pressure greater than $>160 / 100$; systemic or neurological disease; orthopedic impairment; lower extremity fracture within the past 6 months; active treatment for cancer; hearing or sight impairment that could not be corrected; cognitive impairment (Mini-Mental State Exam score $<24$ ); medication use known to affect balance (eg, sedatives); consuming more than 21 alcoholic drinks per week; functional limitations that limit walking ability; and current participation in resistance exercise.

Participants completed the screening questionnaires on demographics, medical history, American Heart Association/ American College of Sports Medicine Health/Fitness Pre-participation Screening Questionnaire, and Mini-Mental State Exam. They also completed measurements of height and body mass and the Short Physical Performance Battery (SPPB), a measurement of lower extremity physical function. ${ }^{29}$

All participants completed a baseline assessment of lower extremity muscle strength and power followed by singlestep balance recovery in the forward and lateral directions, presented in random order. Following baseline testing, participants were randomized to ST or PT for 6 weeks, followed by repeated assessments of muscle strength and power and balance recovery. Members of the research team (DNP, ECH, JAZ) completed all balance recovery assessments and were trained by two investigators (APM and MLM) who have experience in testing older individuals and forward leaning tasks. ${ }^{12,13,18}$ Assessors (DNP and ECH) were trained by an investigator (APM) and completed all strength and power testing procedures. Outcome assessors were not blinded to group assignment; they followed a detailed protocol document for all outcomes assessment designed to mitigate bias in outcomes assessment.

\section{Forward leaning assessment}

Participants were placed in a full-body, non-stretch harness (Miller Fall Protection, Franklin, PA, USA) that was tethered to the ceiling to prevent ground contact in the event of a failed recovery. A safety belt (Miller Fall Protection) was placed around the waist of the participant at the level of the naval. A lean-control cable extended from the back of the belt to a rigid support. A double-caliper release device (Scott Archery, Clay City, KY, USA) was used to release the participant from the forward leaning position.

The forward lean angle was measured from the vertical using a digital inclinometer (Craftsman, Hoffman Estates, IL, 
USA) attached to a $2 \mathrm{~m}$-long straight edge. The participant adjusted their body so that markers on the left acromion process, greater trochanter, and lateral malleolus formed a straight line parallel to the inclinometer when it was placed at the desired angle. Participants were instructed to look straight ahead at a visual target placed on the wall in front of them with their arms folded across their chest while keeping their feet together and flat on the ground with their body mass evenly distributed between both feet. Participants were released after a brief random time delay and instructed to regain their balance by taking a single step with their right leg while leaving the left leg in place. Participants were allowed to move their arms from a folded position to assist with balance recovery.

The criteria for determining a failed trial were adopted from Madigan and $\operatorname{Lloyd}^{13}: 1$ ) taking more than one step with the right leg; 2) moving the left leg from its starting position by more than $30 \%$ of the participant's height; 3 ) falling into the harness or using the harness to regain balance; and 4) being unable to maintain the forward lean angle position prior to cable release.

The starting lean angle was $5^{\circ}$. After a successful recovery with a single step, the lean angle was increased by $2.5^{\circ}$. After a failed recovery, participants were given a second attempt at the same angle. If the participant failed twice at a given angle, they were given a 1- to 2-minute rest, the angle was reduced by $1.25^{\circ}$, and the test was repeated. If this attempt was successful, the angle was increased by increments of $1.25^{\circ}$ until the participant failed to regain their balance. After a 1- to 2-minute rest period, the angle was repeated. The angle at which two failures occurred was deemed the failure angle. The largest angle from which the participant could successfully recover their balance $\left(\right.$ FLean $_{\max }$ ) was used to quantify forward balance recovery ability.

\section{Lateral leaning assessment}

For the lateral leaning assessment, the participant was positioned standing with both feet together and leaning to their right. The position of the safety belt was adjusted so that the lean control cable was positioned in line with the left greater trochanter of the femur. Lateral leaning angle was measured from the vertical using the inclinometer aligned with the sternal notch and umbilicus and a midpoint between the feet. The starting angle was $2.5^{\circ}$, and the lateral leaning angle was adjusted after each trial as previously described in this paper, for forward leaning trials. Participants were instructed to recover their balance with one step to the right with their right foot. The criteria for failure and angle advancement were the same as those for the forward leaning assessment. The largest angle from which the participant could successfully recover their balance $\left(\right.$ LLean $_{\max }$ ) was used to quantify lateral balance recovery ability.

\section{Muscle strength and power testing}

Lower limb muscle strength and power were measured bilaterally using pneumatic leg extension ([LE] AIR250) and leg press ([LP] AIR300) machines (Keiser Corporation, Fresno, CA, USA), using the protocol of Marsh et al. ${ }^{30}$ Subjects completed a 5-minute aerobic warm-up (walking or cycling) and completed a series of lower limb stretches for the quadriceps, hamstrings, calves, and gluteal muscles. The LE and LP machines were adjusted so that the hips and knees were flexed to $90^{\circ}$. Strength was quantified as the maximum resistance $(\mathrm{kg})$ that could be lifted one time using correct form (one repetition maximum [1RM]). Subjects made repeated attempts to lift progressively heavier loads with 2 minutes of rest between efforts until 1RM was achieved. To assess peak power for LE/LP, the resistance was adjusted to $70 \%$ of the 1RM test. The participant was instructed to perform the LE/LP exercise, doing the concentric phase as quickly as possible while controlling the eccentric phase. LE/LP power was quantified as the maximum power (W) of five individual repetitions.

\section{Resistance training intervention}

Participants were randomized to either ST or PT. All participants exercised three times per week (Monday, Wednesday, and Friday) for approximately 1 hour for 6 weeks in groups of four to five participants supervised by two interventionists who were graduate students in exercise science and certified American College of Sports Medicine Exercise Specialists. ST and PT groups completed three sets of training on seven exercises: LP, LE, leg curl, hip abduction, hip adduction, hip flexion, and calf press. The LP and LE were completed on the Keiser machines. The leg curl, hip abduction, hip adduction, and calf press exercises were completed on Nautilus resistance training machines (Nautilus; Med-Fit Systems Inc., Fallbrook, CA, USA). The hip flexion exercise was completed using ankle weights.

Both groups completed two sets of eight to ten repetitions at $50 \%$ of $1 \mathrm{RM}$ based on their baseline measurements. Fifty percent of 1RM was chosen because there is some evidence that lower resistance is best for improving contraction velocity, which is a component of muscle power. ${ }^{31,32}$ During the third set, the participants were instructed to complete as many repetitions as possible with good form as judged by 
the interventionist. If the participant completed more than ten repetitions on the third set, their resistance was increased $5 \%-10 \%$ for the next session. The ST group was instructed to complete the concentric phase of the exercises in 2-3 seconds, whereas the PT group was instructed to complete the concentric phase of contraction "as fast as possible". Both groups were instructed to complete the eccentric phase of contraction in 2-3 seconds. Participants rested for 2-3 minutes between sets and between machines.

\section{Statistical analysis}

Baseline characteristics were summarized by ST and PT groups using means and percentages. The primary outcomes in this study were change in FLean $_{\text {max }}$ and LLean max $_{\text {from }}$ baseline to follow-up. Analysis of covariance (ANCOVA) was used to obtain adjusted estimates of change and to test the difference between the ST group and PT group in the change in outcomes. We used the baseline value of the outcome as a covariate and also included sex as a covariate since randomization was stratified on this characteristic. Residuals from all models were examined for normality of the distribution and outliers, and least squares means and 95\% confidence intervals, adjusting for these covariates, are reported. All analyses were done using SAS software (v 9.3; SAS Institute Inc., Cary, NC, USA). Nominal significance levels are reported; however, as this pilot study was designed to obtain estimates of variances and experience with the protocols, these tests are generally only powered to detect very large differences.

\section{Results}

This study cohort was an ostensibly healthy group of older adults who exhibited some lower extremity mobility dysfunc-

Table I Descriptive statistics at baseline

\begin{tabular}{|c|c|c|c|c|}
\hline \multirow[t]{2}{*}{ Characteristic } & \multicolumn{2}{|c|}{$\begin{array}{l}\text { Strength training } \\
(n=10)\end{array}$} & \multicolumn{2}{|c|}{$\begin{array}{l}\text { Power training } \\
(n=10)\end{array}$} \\
\hline & Mean & $\overline{\text { SD }}$ & Mean & SD \\
\hline Age, years & 68.1 & 3.4 & 73.4 & 3.7 \\
\hline Male, n (\%) & $5(50)$ & & $6(60)$ & \\
\hline $\mathrm{BMI}, \mathrm{kg} / \mathrm{m}^{2}$ & 30.4 & 4.1 & 30.5 & 5.0 \\
\hline Body mass, kg & 85.0 & 11.3 & 92.4 & 20.5 \\
\hline SPPB $^{30}$ score $(0-12)$ & 9.8 & $\mathrm{I} .4$ & 9.3 & 1.2 \\
\hline FLean $_{\max }, \circ$ & 15.5 & 5.0 & 15.9 & 5.2 \\
\hline LLean $_{\max }, \circ$ & 10.0 & 2.5 & 8.5 & 4.0 \\
\hline Leg extension IRM, kg & 37.3 & 21.1 & 37.4 & 24.9 \\
\hline Leg press IRM, kg & 144.3 & 80.3 & 140.2 & 57.1 \\
\hline $\begin{array}{l}\text { Leg extension peak } \\
\text { power, } \mathrm{W}\end{array}$ & 304.0 & 184.2 & 254.2 & 182.9 \\
\hline Leg press peak power, W & 337.3 & 146.6 & 372.9 & 233.7 \\
\hline
\end{tabular}

Abbreviations: BMI, body mass index; SPPB, Short Physical Performance Battery; FLean $_{\max }$, maximum recoverable forward lean angle; LLean ${ }_{\max }$, maximum recoverable lateral lean angle; IRM, one repetition maximum; SD, standard deviation. tion as evidenced by the SPPB score (Table 1). The ST group was an average 5.3 years younger than the PT group and other characteristics were generally balanced between groups at baseline. Five participants (ST: three, PT: two) dropped out of the study and were lost to follow-up. The reasons for drop out were lower extremity injuries not related to the study $(n=3)$ and knee and muscle soreness during training $(n=2)$.

Adherence was assessed by the number of sessions attended divided by the number of possible sessions that could be attended (18 sessions). For all 15 participants who completed baseline and follow-up testing, adherence (mean \pm standard deviation) was $89.0 \% \pm 11.1 \%$. Adherence was $93.0 \% \pm 7.9 \%$ for the ST group and $85.0 \% \pm 12.5 \%$ for the PT group.

LE and LP strength tended to improve in both groups after 6 weeks of training but did not differ between the groups ([Table 2] $P=0.134$ and $P=0.585$, respectively). LE and LP power tended to improve in both groups; there was no statistically significant difference in the change in LE and LP power between groups ( $P=0.602$ and $P=0.989$, respectively). FLean $_{\text {max }}$ improved in the ST group $\left(+4.1^{\circ}[0.7,7.5]\right)$ but the change in FLean max $_{\text {an }}$ wot different between the groups $(P=0.127)$. LLean ${ }_{\max }$ improved in the ST group $(+2.2[0.4$, $4.1])$ and the PT group $(+2.6[0.9,4.4])$, but the change in LLean $_{\max }$ was not different between groups $(P=0.765)$.

Since the magnitude of the changes in FLean ${ }_{\max }$ and LLean $_{\max }$ between groups was similar, and given the preliminary nature of this pilot study, we combined participants into a single group to examine differences pre- to post-intervention. FLean $_{\text {max }}$ increased by $2.4^{\circ}(15 \%$ improvement; $P=0.044)$ and LLean $_{\max }$ increased by $2.4^{\circ}$ (26\% improvement; $\left.P=0.001\right)$. In Table 2, we provide the detectable differences associated with $80 \%$ power (assuming eight per group) and the standard deviations (root mean squared error) that we obtained from the ANCOVAs.

\section{Discussion}

The purpose of this 6-week pilot study was to gain information on the feasibility of these interventions and to obtain estimates of the variances resulting from a shortterm intervention of either PT or ST on single-step balance recovery among older adults in both a forward and lateral direction. While it has been hypothesized that muscle power may be more important than muscle strength in recovery from a slip or trip,,$^{4,6,12,17,30}$ there are no studies in the literature that have attempted to increase muscle strength and power directly and then measure balance recovery performance. The main result from this study was that resistance training 
Table 2 LSMs and 95\% Cls for changes in muscle strength, muscle power, and maximum lean angles for the ST and PT groups

\begin{tabular}{|c|c|c|c|c|c|c|c|c|}
\hline $\begin{array}{l}\text { Dependent } \\
\text { variable }\end{array}$ & $\begin{array}{l}\text { ST group } \\
\text { LSM (CI) }\end{array}$ & $\begin{array}{l}\text { PT group } \\
\text { LSM (CI) }\end{array}$ & $\begin{array}{l}\text { Difference in } \\
\operatorname{LSM}(\mathrm{Cl})\end{array}$ & $\begin{array}{l}P \text {-value } \\
\text { difference }\end{array}$ & $\begin{array}{l}\text { Root } \\
\text { MSE }\end{array}$ & $\begin{array}{l}\text { Detectable } \\
\text { difference with } \\
80 \% \text { power }\end{array}$ & $\begin{array}{l}\text { Estimate of } \\
\text { overall change } \\
\text { LSM (CI) }\end{array}$ & $\begin{array}{l}P \text {-value } \\
\text { for overall } \\
\text { change }\end{array}$ \\
\hline $\begin{array}{l}\text { Change in LE } \\
\text { strength, } \mathrm{kg}\end{array}$ & $5.8(-0.2,11.7)$ & I I.8 (6.2, I7.4) & $-6.0(-14,2.2)$ & 0.1336 & 7.15 & 11.22 & $8.8(4.7,12.9)$ & 0.0006 \\
\hline $\begin{array}{l}\text { Change in LP } \\
\text { strength, } \mathrm{kg}\end{array}$ & $22.4(-10,55.1)$ & $33.9(3.3,64.4)$ & $-11.5(-56,33.3)$ & 0.5845 & 39.17 & 61.45 & $28.1(5.8,50.5)$ & 0.0181 \\
\hline $\begin{array}{l}\text { Change in LE } \\
\text { power, W }\end{array}$ & $53.1(9.7,96.5)$ & $67.7(27.4,108)$ & $-14.6(-75,45.3)$ & 0.6019 & 51.21 & 80.34 & $60.4(31.2,89.6)$ & 0.0008 \\
\hline $\begin{array}{l}\text { Change in LP } \\
\text { power, } W\end{array}$ & $95.9(12.1,180)$ & $96.6(18.2,175)$ & $-0.7(-116,114)$ & 0.9889 & $100.5 \mid$ & 157.68 & $96.2(38.9,154)$ & 0.0035 \\
\hline $\begin{array}{l}\text { Change in } \\
\text { FLean }_{\max }{ }^{\circ}\end{array}$ & 4.I $(0.7,7.5)$ & $0.6(-2.5,3.8)$ & $3.5(-1.2,8.1)$ & 0.1270 & 4.04 & 6.34 & $2.4(0.1,4.7)$ & 0.0442 \\
\hline $\begin{array}{l}\text { Change in } \\
\text { LLean }_{\max }{ }^{\circ}\end{array}$ & $2.2(0.4,4.1)$ & $2.6(0.9,4.4)$ & $-0.4(-3.1,2.3)$ & 0.7652 & 2.12 & 3.33 & $2.4(1.2,3.6)$ & 0.0010 \\
\hline
\end{tabular}

Notes: All estimates adjusted for sex and the baseline measurement value of the dependant variable. Estimates of overall change obtained as average of LSM values.

Abbreviations: LSM, least squares mean; $\mathrm{Cl}$, confidence interval; ST, strength training; PT, power training; LE, leg extension; LP, leg press; FLean max maximum recoverable forward lean angle; LLean ${ }_{\text {max }}$, maximal lateral lean angle; MSE, mean squared error.

in general may be a suitable method of improving balance recovery with a single step, and that short-term ST and PT do not differ in their effect on single-step recovery in the forward or lateral direction.

The FLean ${ }_{\text {max }}$ of $15.5^{\circ}-16^{\circ}$ at baseline for our older male and female sample was comparable to data previously reported. ${ }^{33}$ A number of cross-sectional studies have examined the role that muscle strength plays in the single-step balance recovery performance, with mixed results. ${ }^{15,18,33}$ Given the proposed importance of muscle power in situations in which rapid movement is required to recover, ${ }^{4,6,12}$ we were interested to see if there was any evidence that the PT group would exhibit larger changes in FLean max $_{\text {and LLean }}$ max $_{\text {compared }}$ to the ST group. There were no statistically significant differences in change scores of FLean ${ }_{\max }$ and LLean ${ }_{\max }$ between the ST group and the PT group following 6 weeks of ST or PT. There are several possible explanations for this result. Although muscle power increased following the intervention, these changes were comparable between the groups. Our intervention was only 6 weeks in length and produced

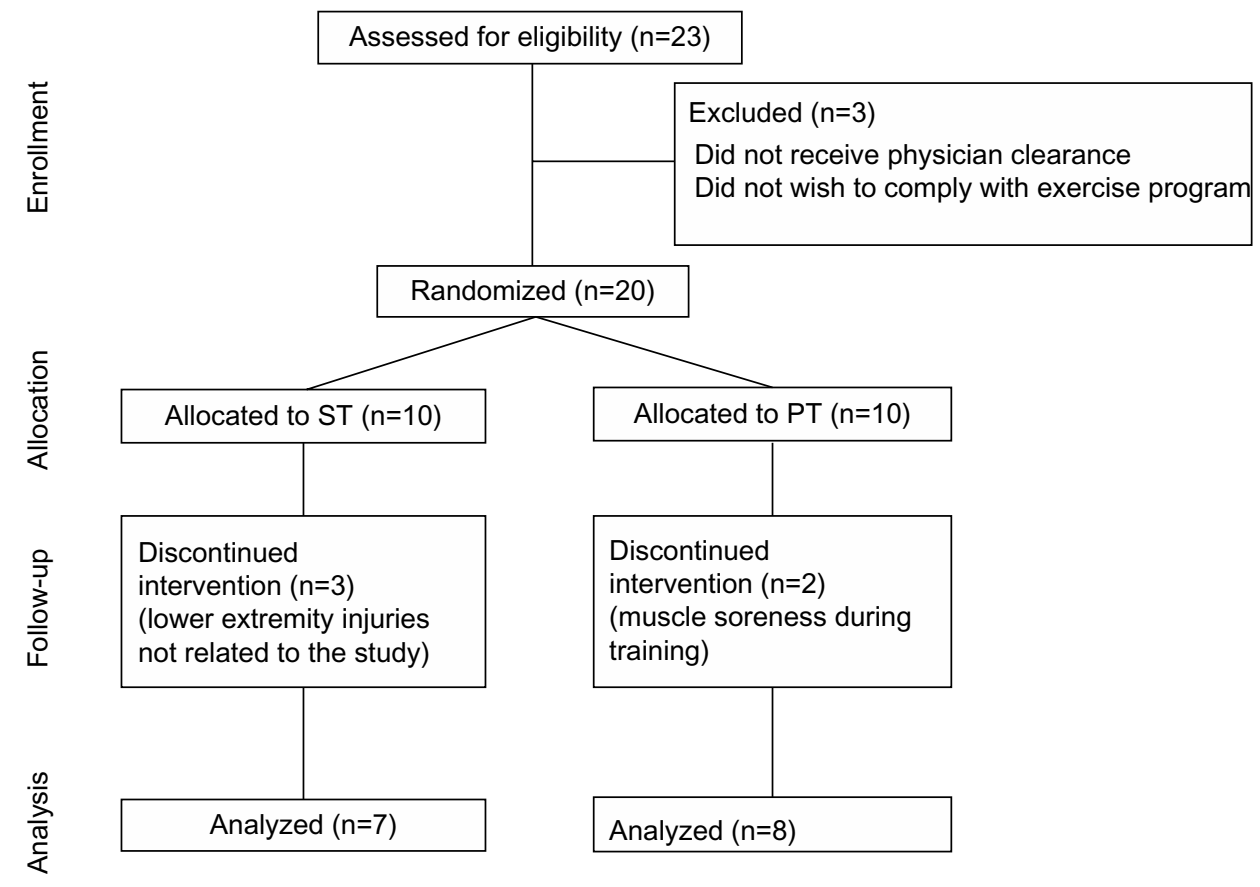

Figure I Flow diagram of participant progress.

Abbreviations: PT, power training; ST, strength training. 
relatively modest increases $(20 \%-30 \%)$ in muscle strength and power. Previous research suggests that interventions of 8-12 weeks may produce greater changes in muscle strength and power, in the order of $30 \%-40 \%{ }^{30} \mathrm{~A}$ longer intervention may better differentiate the ST and PT groups with respect to changes in muscle strength and power. Participants in the PT group completed their exercises at $50 \%$ of their baseline $1 \mathrm{RM}$ and resistance was increased for the following session if they performed more than ten repetitions in the final set. However, some research indicates that a lower resistance of 20\%-40\% 1RM during PT may lead to greater improvements in contraction velocity - a component of muscle power compared to higher resistances. ${ }^{31}$

Recently, Arampatzis et $\mathrm{al}^{34}$ reported that a training program consisting of exercises for dynamic stability and neuromuscular control improved performance on a forward leaning task. Recovering balance from a large postural perturbation requires a dynamic response involving different movement patterns and strategies, ${ }^{23}$ where speed of movement and lower extremity coordination are important determinants of recovery success. ${ }^{14}$ Future work should consider the addition of dynamic stability in combination with ST or PT.

The exercises we selected for the ST and PT interventions were based on typical lower extremity resistance training tasks, although we did include the hip flexor exercise since it is important in initiating the forward movement of the stepping leg. Interestingly, recent work by Graham et $\mathrm{al}^{35}$ showed that the hip abductors generated the largest muscle force relative to other muscles in the lower extremity during single-step recovery in old and young adults. They suggest that muscle weakness of the hip abductors could be a factor limiting recovery from a forward loss of balance. Therefore, the hip abductors may be a muscle group to specifically target for intervention in future work.

The results of this preliminary study are best interpreted within the context of its strength and limitations. Although the single-step balance recovery method employed here is well accepted, the relationship between it and risk of falls has not been established. Also, our recovery failure criteria did not allow for multiple-step recoveries, and older adults report greater difficulty recovering balance with a single step. ${ }^{36}$ It may be that a single step is not a natural strategy for some participants, which may have negatively influenced their performance on the leaning tasks. ${ }^{35}$ Although participants were randomly assigned to ST or PT, the ST group was an average 5.3 years younger than the PT group $(P=0.004)$, which may have biased our results in favor of the ST group. Attrition $(n=5)$ diminished our power to detect differences between the ST and PT groups. Although two participants dropped out as a result of joint and muscle soreness attributed to the intervention, resistance exercise is generally very well tolerated by older adults and has been shown to be safe in a large number of studies. ${ }^{30-32}$

Our sample exhibited some degree of lower extremity functional limitations as evidenced by the mean SPPB score of 9.2, but the sample were not considered high-fall-risk participants. For example, our sample did not have a history of falling, and participants were excluded if they were at high risk for falls (eg, due to neurologic disorders, sedative medications, inability to walk, etc). This was a precautionary decision on our part. It is unclear if the effects of PT and ST estimated here would differ among high-fall-risk participants. Our study did not employ a control group that received no intervention. Since we were primarily interested in estimating variances and gaining experience in the feasibility of our testing and PT and ST training protocols, we chose not to use a control group and treated ST as standard care since it is recommended as part of a complete physical activity regimen by the American College of Sports Medicine and American Heart Association. ${ }^{37}$ While we were interested in comparing the effectiveness of ST and PT, it is possible that participants experienced a learning effect from repeating the leaning tasks, and future studies should incorporate a control group into the study design. Likewise, it would be ideal if all assessment staff were blinded to intervention group to minimize the potential for bias. To follow up on this issue in our sample, we performed Wilcoxon two-sample tests, which showed that there was no statistically significant difference in the number of trials needed to reach FLean ${ }_{\max }$ or LLean $_{\text {max }}$ between pre- and posttest measures (FLean ${ }_{\max }: 10.3$ versus 10.3; $P=0.259$. LLean ${ }_{\max }: 7.1$ versus $\left.9.9 ; P=0.730\right)$. Also, the length of time before the perturbation during the leaning tasks was random and we did not observe anticipation by the participants. Recently, Arampatzis et $\mathrm{al}^{34}$ observed no change in balance recovery performance in a control group over a 14-week follow-up. To our knowledge, learning effects from repeated trials of single-step recovery tasks have only been identified within single sessions, ${ }^{10,38}$ and our testing sessions were separated by 6 weeks.

\section{Conclusion}

We did not find that PT resulted in substantially greater improvements compared to ST in single-step balance recovery. The magnitude of the improvements in muscle strength and power and balance recovery performance when we combined the sample into a single group provided some 
support for the use of resistance training in older adults to enhance single-step balance recovery. Further research with a larger sample and a longer intervention is needed to determine if PT is superior to ST for balance recovery in older adults. In the interim, our data suggest that resistance training, in general, is beneficial and should be encouraged as part of an older adult's physical activity regimen, as muscular weakness remains an important risk factor for falls. ${ }^{39}$

\section{Acknowledgments}

Drs Anthony P Marsh and Michael E Miller are supported by the WFU Claude D. Pepper Center National Institutes for Aging Grant number P30 AG021332.

\section{Disclosure}

The authors report no conflicts of interest in this work. The authors do not have any financial or personal relationships with other people or organizations that could inappropriately influence (bias) their work.

\section{References}

1. Parkkari J, Kannus P, Palvanen M, et al. Majority of hip fractures occur as a result of a fall and impact on the greater trochanter of the femur: a prospective controlled hip fracture study with 206 consecutive patients. Calcif Tissue Int. 1999;65(3):183-187.

2. Magaziner J, Lydick E, Hawkes W, et al. Excess mortality attributable to hip fracture in white women aged 70 years and older. Am J Public Health. 1997;87(10):1630-1636.

3. Stevens JA, Corso PS, Finkelstein EA, Miller TR. The costs of fatal and non-fatal falls among older adults. Inj Prev. 2006;12(5):290-295.

4. Mayson DJ, Kiely DK, LaRose SI, Bean JF. Leg strength or velocity of movement: which is more influential on the balance of mobility limited elders? Am J Phys Med Rehabil. 2008;87(12):969-976.

5. Moreland JD, Richardson JA, Goldsmith CH, Clase CM. Muscle weakness and falls in older adults: a systematic review and meta-analysis. J Am Geriatr Soc. 2004;52(7):1121-1129.

6. Perry MC, Carville SF, Smith IC, Rutherford OM, Newham DJ. Strength, power output and symmetry of leg muscles: effect of age and history of falling. Eur J Appl Physiol. 2007;100(5):553-561.

7. Wolfson L, Judge J, Whipple R, King M. Strength is a major factor in balance, gait, and the occurrence of falls. J Gerontol A Biol Sci Med Sci. 1995;50 Spec No:64-67.

8. Carbonneau E, Smeesters C. Effects of age and lean direction on the threshold of single-step balance recovery in younger, middle-aged and older adults. Gait Posture. 2014;39(1):365-371.

9. Carty CP, Barrett RS, Cronin NJ, Lichtwark GA, Mills PM. Lower limb muscle weakness predicts use of a multiple- versus single-step strategy to recover from forward loss of balance in older adults. J Gerontol A Biol Sci Med Sci. 2012;67(11):1246-1252.

10. Carty CP, Cronin NJ, Lichtwark GA, Mills PM, Barrett RS. Mechanisms of adaptation from a multiple to a single step recovery strategy following repeated exposure to forward loss of balance in older adults. PloS One. 2012;7(3):e33591.

11. Carty CP, Mills P, Barrett R. Recovery from forward loss of balance in young and older adults using the stepping strategy. Gait Posture. 2011;33(2):261-267.

12. Madigan ML. Age-related differences in muscle power during single-step balance recovery. $J$ Appl Biomech. 2006;22(3):186-193.
13. Madigan ML, Lloyd EM. Age and stepping limb performance differences during a single-step recovery from a forward fall. $J$ Gerontol A Biol Sci Med Sci. 2005;60(4):481-485.

14. Thelen DG, Wojcik LA, Schultz AB, Ashton-Miller JA, Alexander NB. Age differences in using a rapid step to regain balance during a forward fall. J Gerontol A Biol Sci Med Sci. 1997;52(1): M8-M13.

15. Wojcik LA, Thelen DG, Schultz AB, Ashton-Miller JA, Alexander NB. Age and gender differences in single-step recovery from a forward fall. J Gerontol A Biol Sci Med Sci. 1999;54(1):M44-M50.

16. Wojcik LA, Thelen DG, Schultz AB, Ashton-Miller JA, Alexander NB. Age and gender differences in peak lower extremity joint torques and ranges of motion used during single-step balance recovery from a forward fall. J Biomech. 2001;34(1):67-73.

17. Carty CP, Cronin NJ, Lichtwark GA, Mills PM, Barrett RS. Lower limb muscle moments and power during recovery from forward loss of balance in male and female single and multiple steppers. Clin Biomech (Bristol, Avon). 2012;27(10):1031-1037.

18. Madigan ML, Lloyd EM. Age-related differences in peak joint torques during the support phase of single-step recovery from a forward fall. J Gerontol A Biol Sci Med Sci. 2005;60(7):910-914.

19. Grabiner MD, Koh TJ, Lundin TM, Jahnigen DW. Kinematics of recovery from a stumble. J Gerontol. 1993;48(3):M97-M102.

20. Pavol MJ, Owings TM, Foley KT, Grabiner MD. Mechanisms leading to a fall from an induced trip in healthy older adults. $J$ Gerontol $A$ Biol Sci Med Sci. 2001;56(7):M428-M437.

21. Blake AJ, Morgan K, Bendall MJ, et al. Falls by elderly people at home: prevalence and associated factors. Age Ageing. 1988;17(6):365-372.

22. Lord SR, Rogers MW, Howland A, Fitzpatrick R. Lateral stability, sensorimotor function and falls in older people. J Am Geriatr Soc. 1999;47(9):1077-1081.

23. Maki BE, McIlroy WE. Control of rapid limb movements for balance recovery: age-related changes and implications for fall prevention. Age Ageing. 2006;35 Suppl 2:ii12-ii18.

24. Rogers MW, Hedman LD, Johnson ME, Cain TD, Hanke TA. Lateral stability during forward-induced stepping for dynamic balance recovery in young and older adults. J Gerontol A Biol Sci Med Sci. 2001;56(9):M589-M594.

25. Rogers MW, Mille ML. Lateral stability and falls in older people. Exerc Sport Sci Rev. 2003;31(4):182-187.

26. Maki BE, Holliday PJ, Topper AK. A prospective study of postural balance and risk of falling in an ambulatory and independent elderly population. J Gerontol.1994;49(2):M72-M84.

27. Mille ML, Johnson ME, Martinez KM, Rogers MW. Age-dependent differences in lateral balance recovery through protective stepping. Clin Biomech (Bristol, Avon). 2005;20(6):607-616.

28. Feldman F, Robinovitch SN. Reducing hip fracture risk during sideways falls: evidence in young adults of the protective effects of impact to the hands and stepping. J Biomech. 2007;40(12):2612-2618.

29. Guralnik JM, Simonsick EM, Ferrucci L, et al. A short physical performance battery assessing lower extremity function: association with self-reported disability and prediction of mortality and nursing home admission. J Gerontol. 1994;49(2):M85-M94.

30. Marsh AP, Miller ME, Rejeski WJ, Hutton SL, Kritchevsky SB. Lower extremity muscle function after strength or power training in older adults. J Aging Phys Act. 2009;17(4):416-443.

31. Orr R, de Vos NJ, Singh NA, Ross DA, Stavrinos TM, FiataroneSingh MA. Power training improves balance in healthy older adults. J Gerontol A Biol Sci Med Sci. 2006;61(1):78-85.

32. Sayers SP. High velocity power training in older adults. Curr Aging Sci. 2008;1(1):62-67.

33. Grabiner MD, Owings TM, Pavol MJ. Lower extremity strength plays only a small role in determining the maximum recoverable lean angle in older adults. J Gerontol A Biol Sci Med Sci. 2005;60(11):1447-1450.

34. Arampatzis A, Peper A, Bierbaum S. Exercise of mechanisms for dynamic stability control increases stability performance in the elderly. J Biomech. 2011;44(1):52-58. 
35. Graham DF, Carty CP, Lloyd DG, Lichtwark GA, Barrett RS. Muscle contributions to recovery from a forward loss of balance by stepping. J Biomech. 2014;47(3):667-674.

36. Luchies CW, Alexander NB, Schultz AB, Ashton-Miller J. Stepping responses of young and old adults to postural disturbances: kinematics. J Am Geriatr Soc. 1994;42(5):506-512.

37. Nelson ME, Rejeski WJ, Blair SN, et al. Physical activity and public health in older adults: recommendation from the American College of Sports Medicine and the American Heart Association. Med Sci Sports Exerc. 2007;39(8):1435-1445.
38. Barrett RS, Cronin NJ, Lichtwark GA, Mills PM, Carty CP. Adaptive recovery responses to repeated forward loss of balance in older adults. J Biomech. 2012;45(1):183-187.

39. [No authors listed]. Guideline for the prevention of falls in older persons. American Geriatrics Society, British Geriatrics Society, and American Academy of Orthopaedic Surgeons Panel on Falls Prevention. J Am Geriatr Soc. 2001;49(5):664-672.

\section{Publish your work in this journal}

Clinical Interventions in Aging is an international, peer-reviewed journal focusing on evidence-based reports on the value or lack thereof of treatments intended to prevent or delay the onset of maladaptive correlates of aging in human beings. This journal is indexed on PubMed Central, MedLine, the American Chemical Society's 'Chemical Abstracts Ser- vice' (CAS), Scopus and the Elsevier Bibliographic databases. The manuscript management system is completely online and includes a very quick and fair peer-review system, which is all easy to use. Visit http://www.dovepress.com/testimonials.php to read real quotes from published authors.

Submit your manuscript here: http://www.dovepress.com/clinical-interventions-in-aging-journal 